\title{
A Technical Overview of the Kentucky Mesonet
}

\author{
Rezaul Mahmood, ${ }^{a}$ Megan Schargorodski, Stuart Foster, And Andrew Quilligan \\ Kentucky Climate Center, and Department of Geography and Geology, Western Kentucky University, Bowling Green, Kentucky
}

(Manuscript received 6 November 2018, in final form 29 March 2019)

\begin{abstract}
The Kentucky Mesonet is a research-grade weather and climate observing network with redundant sensors that monitors the near-surface atmosphere at 71 locations across Kentucky. The network measures temperature, precipitation, solar radiation, relative humidity, barometric pressure, and wind speed and direction every $5 \mathrm{~min}$, with soil moisture and soil temperature measured every $30 \mathrm{~min}$. In addition, it operates a camera at selected locations. All observations are transmitted via cellular modem every $5 \mathrm{~min}$ and become available to the general public through the World Wide Web within seconds after arrival at Kentucky Mesonet's Network Operations Center. In between arriving at the IT division and dissemination to general public, the data also go through automated data quality assurance (QA) procedures. Within that time, the data can be viewed through various graphical/visualization formats, developed based on feedback from the user community. The Kentucky Mesonet produces twice-daily QA reports and its technicians respond to these reports, making site visits when necessary to address issues. Mesonet technicians make regular site visits to all stations during spring, summer, and fall seasons. The network maintains a detailed database of station metadata that includes instrument and site maintenance history. The Mesonet delivers the data to the National Weather Service to aid forecasting. It also works closely with a variety of local, state, and federal entities so that the network can meet diverse needs.
\end{abstract}

\section{Introduction}

Weather and climate monitoring have progressively become more important. This particularly became noticeable in the second half of the twentieth century with the launching of weather-observing satellites and establishment of improved and new in situ observation platforms. Historically, these efforts were funded by respective national governments, including the United States. The federally funded Cooperative Observer Program (COOP) network of the National Weather Service (NWS) has been the backbone of in situ observations for more than a century in the United States (Menne et al. 2009; Fiebrich and Crawford 2009; Leeper et al. 2015). This network primarily collects daily maximum and minimum temperature and precipitation. The U.S. Climate Reference Network (USCRN) was subsequently developed, capitalizing upon advances in

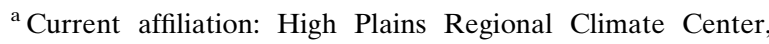
School of Natural Resources, University of Nebraska-Lincoln, Lincoln, Nebraska.
}

Corresponding author: Rezaul Mahmood,rmahmood2@unl.edu instrumentation technology and emphasizing the role of high-quality site exposures to address needs for observational accuracy in climate monitoring (Diamond et al. 2013). The focus of this network is continental-scale monitoring with over 130 stations (Leeper et al. 2015).

However, over recent decades, the availability of funding has progressively declined for operation, expansion, or upgrade of existing observation platforms. At the same time, the need for high-quality data in near-real time to support applications at mesoscale has become more pressing for a wide variety of users and decision-makers. Given this situation, combined with better understanding of socioeconomic relevance and the value of accurate and timely weather and climate information (Ziolkowska et al. 2017), various entities at the national and subnational levels have attempted to improve and/or develop their own weather and climate monitoring networks to address their decision-making needs (e.g., Hubbard et al. 1983; Meyer and Hubbard 1992; Brock et al. 1995; Tucker 1997; Brown and Hubbard 2001; Horel et al. 2002).

Development of mesoscale weather and climate monitoring in Kentucky (www.kymesonet.org) is a result of such needs. The mesoscale refers to a $\sim 30-\mathrm{km}(\sim 20-\mathrm{mi})$ 


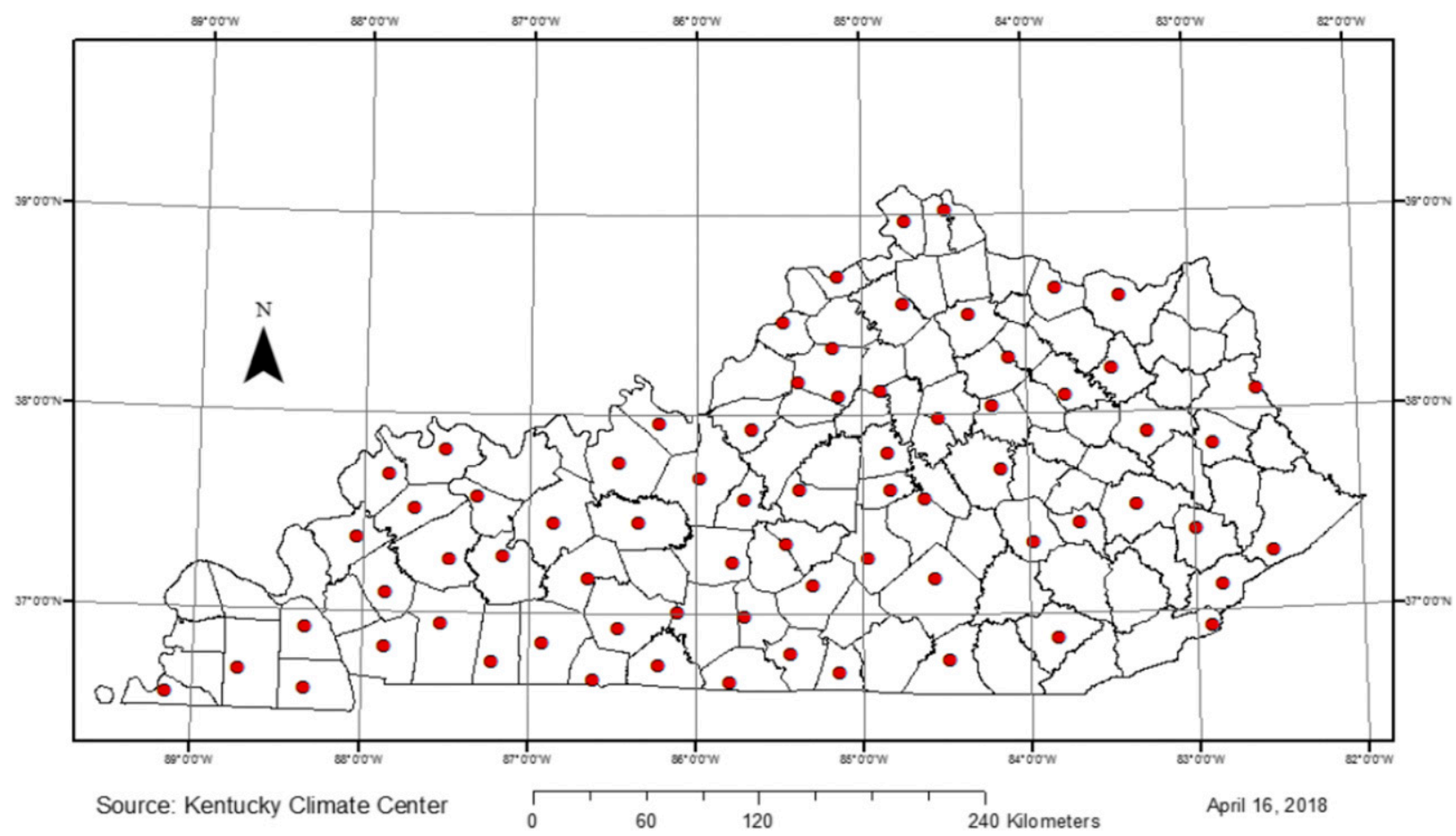

FIG. 1. Kentucky Mesonet station locations.

area around a location. It is generally understood that observations at this scale provide weather and climate information that can be useful for a variety of decisionmaking. Hence, the term "Kentucky Mesonet" refers to the mesoscale weather and climate monitoring network for Kentucky. The objective of this paper is to provide a technical overview of the Kentucky Mesonet. Similar assessments of other mesonets have been provided, for example, by Brock et al. (1995), Kimball et al. (2010), Schroeder et al. (2005), and Shulski et al (2018). Additionally, an overview of the mesonets in the United States can be found in Mahmood et al. (2017).

The Kentucky Mesonet established its first station in 2007 in Bowling Green, Kentucky, and reached 65 station installations in 2012. Currently, Kentucky Mesonet operates 71 stations and is expanding (Fig. 1). All of its stations observe and collect 5-min data for temperature, precipitation, relative humidity, wind speed and direction, and solar radiation. Currently, 35 of the 71 stations collect soil moisture and temperature data at up to five depths below surface the $(5,10,20,50$, and $100 \mathrm{~cm})$, 40 stations observe atmospheric pressure, and 13 have camera observations. The instrumentation platform continues to expand as funding becomes available. Figures $2 \mathrm{a}-\mathrm{c}$ provide a station photo and relative position of instruments at a site. These data are distributed to the public through the World Wide Web in near-real time (Fig. 3). The following sections will provide detailed discussions on the Kentucky Mesonet site selection, sensors, communication, data quality assurance procedures, and applications with a conclusion highlighting the state of the network.

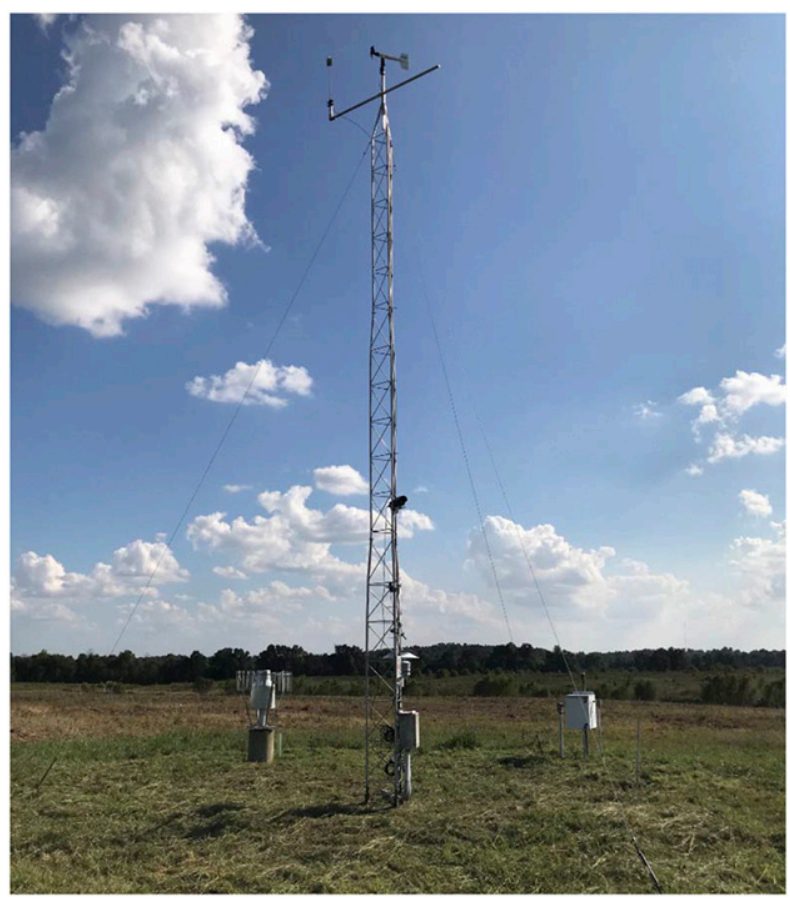

FIG. 2a. A Kentucky Mesonet station. 


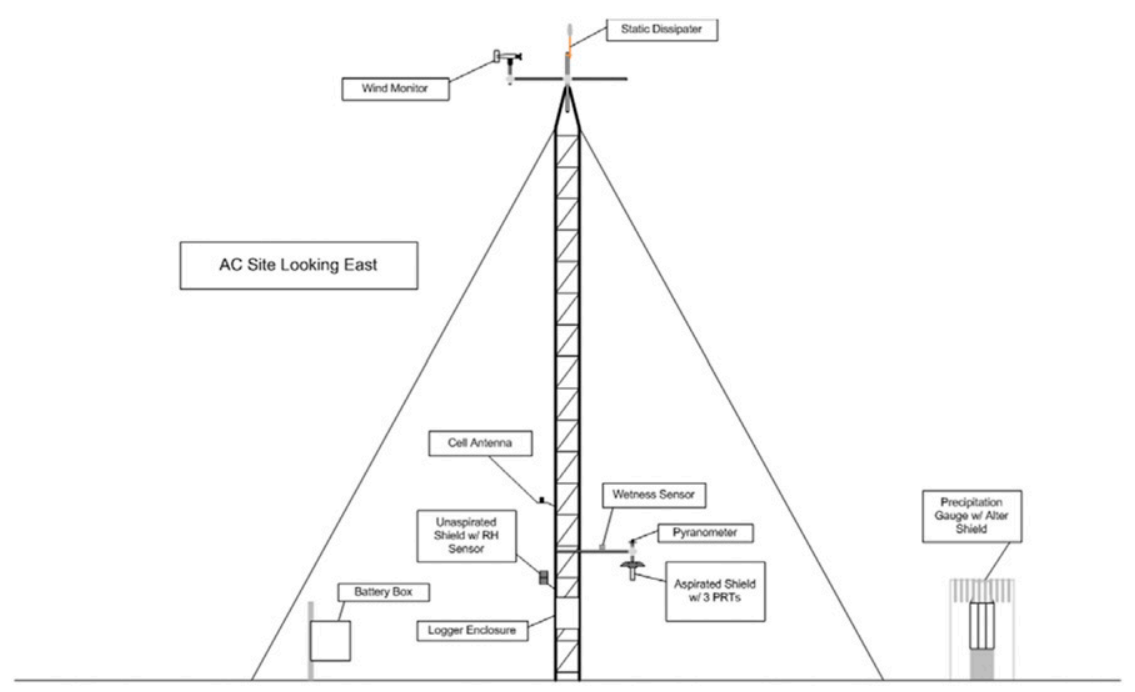

FIG. 2b. Sketch of the tower and instrumentation for a Kentucky Mesonet station.

\section{Site selection}

The value of data from an in situ weather and climate monitoring network depends upon the representativeness of site-specific observations relative to surrounding areas and the needs of users of those observations. On an isotropic plane and with free access, monitoring sites would be positioned according to a tessellation of uniform squares or hexagons. The representativeness of a given observing site would decay as a function of distance from that site. In practice, the spatial distribution of monitoring sites in the Kentucky Mesonet reflects influences of factors including terrain, community support, and property access.

Kentucky is characterized by complex and diverse terrain, as described by topography and land use/land cover. Flat to rolling cropland prevails in the western portion, with elevation near $90 \mathrm{~m}(300 \mathrm{ft})$ and relief mostly less than $30 \mathrm{~m}$ (100 ft). Topography becomes more rolling in the central region and cropland increasingly gives way to pastureland. The eastern region is predominantly characterized by steeply sloping, forested hills and cleared valleys of the dissected Appalachian Plateau, with hilltop and ridgeline elevations near $600 \mathrm{~m}(2000 \mathrm{ft})$ and valleys with elevations near $300 \mathrm{~m}(1000 \mathrm{ft})$. Rural population and small towns are concentrated in the valleys. Slopes become steeper and valleys narrower toward the southeast. The southeastern corner is transected by a linear ridge-and-valley system, with a peak elevation exceeding

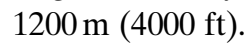

Topography has a discernible influence on local climates and thus the representativeness of in situ observations. Boundary layer atmospheric conditions vary significantly from ridgetops to valley bottoms, depending upon the synoptic weather pattern and the diurnal cycle. In regions of the state where relief is more prominent, a concerted effort is made to pair stations in adjacent counties, such that both ridge and valley sites are monitored. Temperature differences between ridge and valley sites often reach $5^{\circ} \mathrm{C}$ and sometimes as much as $15^{\circ} \mathrm{C}$ during overnight hours. The site selection process is thus complicated by the realization that the representativeness of a proximate monitoring site is not a simple function of distance.

During the initial buildout phase of the Kentucky Mesonet, site selection kickoff meetings were organized and hosted by Kentucky's 15 Area Development Districts (ADDs), each of which engages local, state, and federal officials in collaborative initiatives to advance economic development and enhance quality of life. This provided an opportunity to inform local stakeholders about requirements and strategies for site selection. Requirements were based on criteria regarding station site exposure provided by the World Meteorological Organization (2014) and the USCRN (Diamond et al. 2013). Strategies involved reliance on local stakeholders to help identify candidate sites and provide qualitative guidance regarding the comparative value of those sites to local communities.

Collaborative efforts involving representatives of the Kentucky Mesonet and local stakeholders led to the identification of candidate sites designated by locational coordinates obtained using a global positioning system device. Candidate sites were georeferenced and screened relative to aerial photography and other base-map layers in a geographic information system. Site visits 


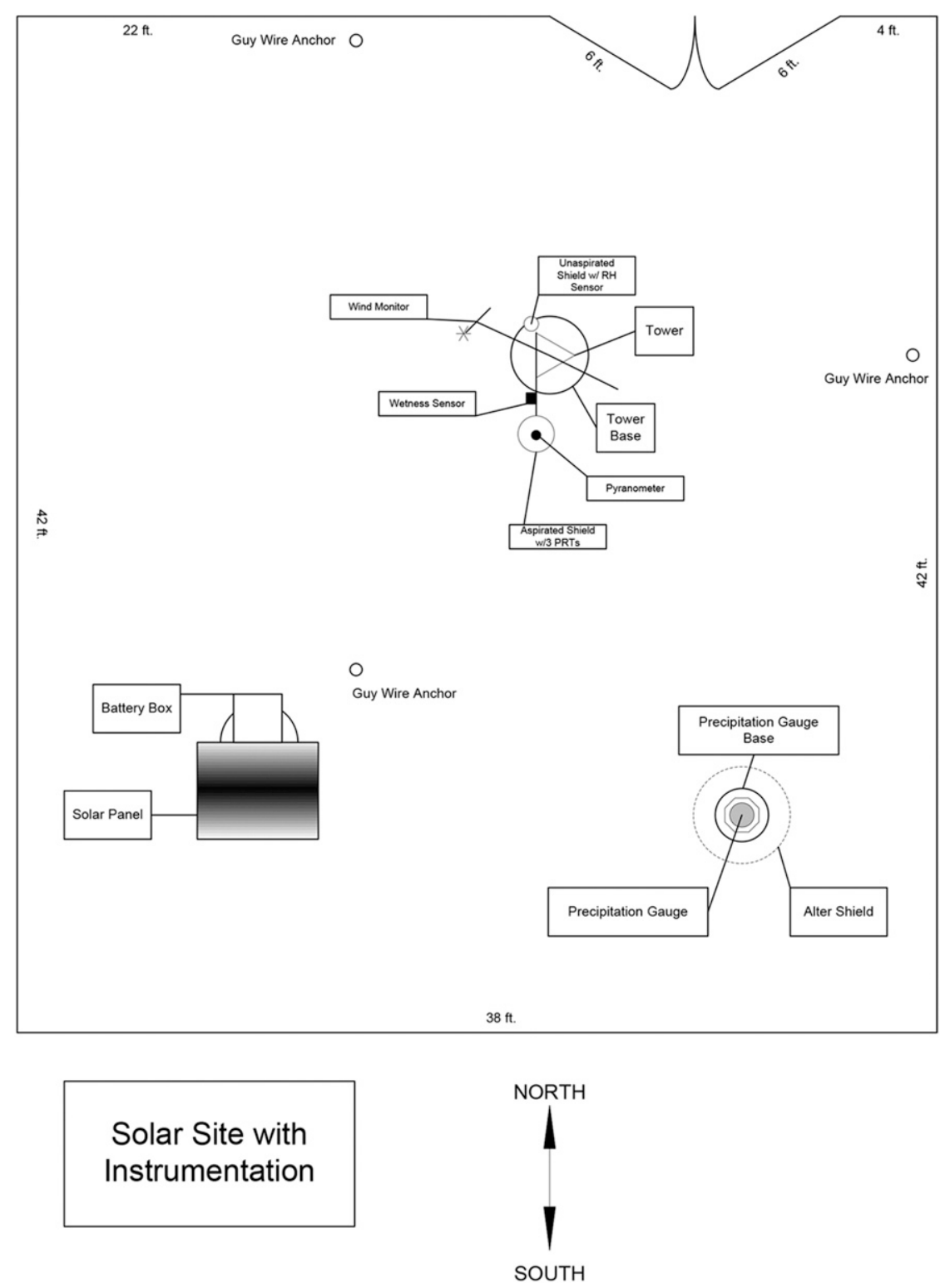

FIG. 2c. Station footprint for a Kentucky Mesonet station.

were then made to selected candidate sites. Local officials often accompanied a Mesonet representative on site visits, providing an opportunity to gauge local priorities and commitment. Ideally, multiple candidate sites were surveyed before selecting the preferred site option. Sites were scored on a 100-point scale partitioned among suitability for temperature (40 points), precipitation (30 points), wind (15 points), and soil (15 points), with scoring based on considerations related to effects of topography, soils, and proximity to obstructions on the quality of the site exposure. In addition to this score, the selection factors included quality of the site exposure, representativeness of the site with respect to local and regional terrain, value of the site location relative to the local population, expected site stability based on the perceived likelihood of future land-use or ownership change, and the need to treat the station as part of a station pairing. The Kentucky Mesonet is fortunate that it is in the process of relocating only two stations since its existence.

The availability of high-quality monitoring sites varied in relation to terrain and land use across Kentucky. On flat to gently undulating terrain where extensive row-crop agriculture was dominant, high-quality sites could be identified, but they were often unavailable. Areas of rolling pastureland provided greater availability of sites. Areas of 


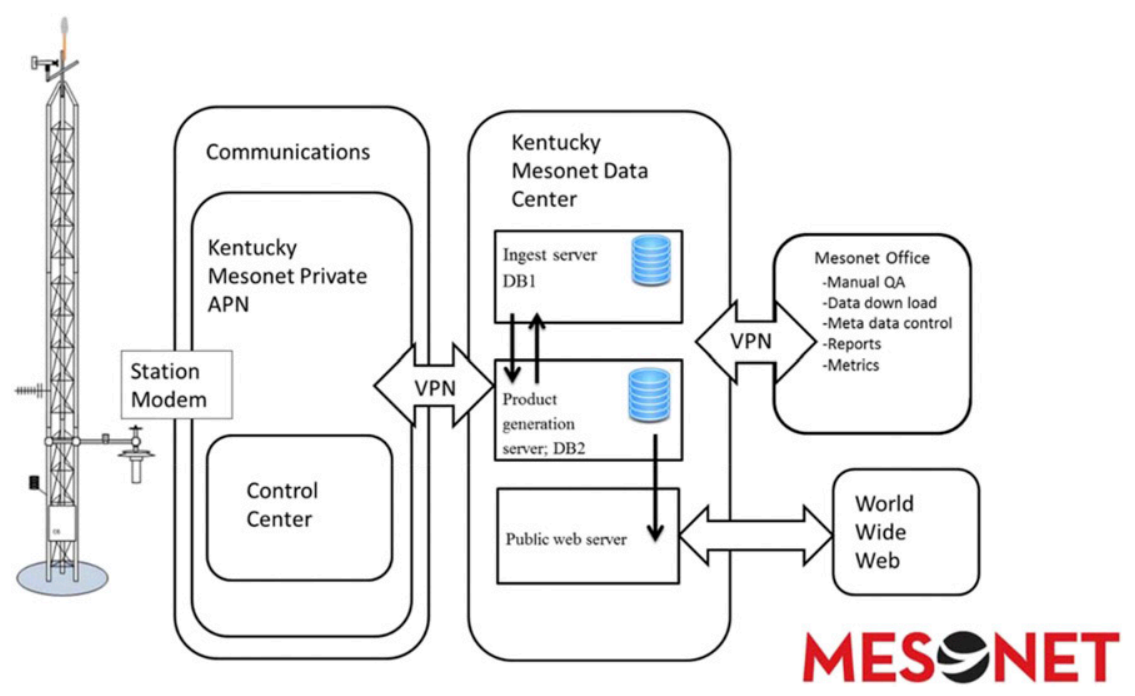

FIG. 3. A flowchart of data collection, communication, processing, and presentation.

rugged terrain presented the greatest difficulty for station siting. These areas of Kentucky are densely forested, while offering few flat, open exposures.

Collectively, the monitoring sites of the Kentucky Mesonet sample a diversity of local climates, which is critical in providing a representative distribution, while also highlighting the importance of metadata for station siting and exposure. Metadata includes a collection of directional site photographs that provide a qualitative assessment of local terrain relative to the site. These photos are supplemented by aerial photography and information extracted from a digital elevation model in a geographic information system.

In summary, through the strategic selection of stations, often involving interdependence with neighboring stations, the Kentucky Mesonet provides a diverse sampling of the underlying atmospheric conditions of the state. This approach fundamentally depends upon the collection and representation of detailed station metadata for each site so that observations can be interpreted with respect to their locational context.

\section{Station layout and sensors}

\section{a. Temperature}

At each station, three Thermometrics Platinum Resistance Thermometers (PRT) temperature sensors (referred to as TA01, TA02, and TA03) are mounted within a single MetOne 076B Aspirated Shield (Fig. 4; Tables 1 and 2). Air is sampled every $3 \mathrm{~s}$ and the datalogger averages 100 values over each 5 -min period to provide a 5-min temperature average for each of the three sensors. Subsequently, averages from the three PRT sensors are averaged to get the official Kentucky Mesonet air temperature (TAIR) for the given time and station. The aspirated shield fan speeds are examined as well. The primary fan should exhibit speeds between 90 and 150 revolutions per minute, with the secondary fan zero. The three sensors should be within $0.3^{\circ} \mathrm{C}$ of each other.

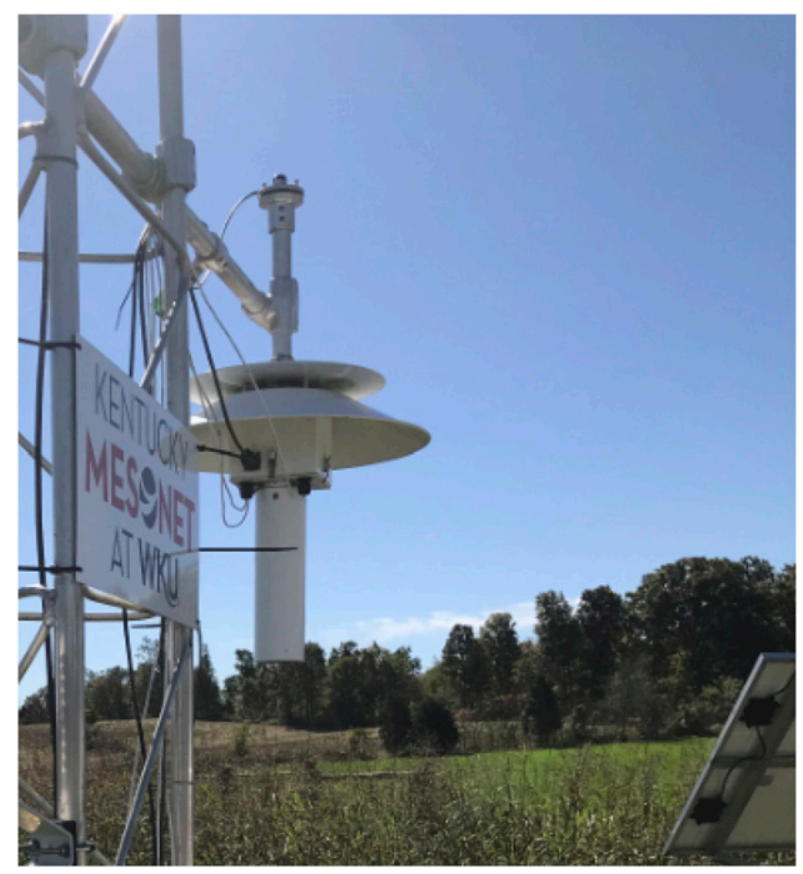

FIG. 4. Aspirated shield that houses three temperature sensors. 
TABLE 1. Instrumentation for Kentucky Mesonet stations.

\begin{tabular}{|c|c|}
\hline & Instrument (rotation interval) \\
\hline \multicolumn{2}{|l|}{ Parameter } \\
\hline Air temperature, fan aspirated & Thermometrics Platinum Resistance Thermometer ( 3 years) \\
\hline Aspirated radiation shield & Met One 076-B fan-aspirated radiation shield ( 8 years) \\
\hline Air temperature and relative humidity, naturally aspirated & Campbell Scientific EE-181 temperature/humidity sensor (2 years) \\
\hline Unaspirated radiation shield & RM Young 10-Plate Solar Radiation Shield \\
\hline Wind speed and direction & RM Young 05103 Wind Monitor (5 years) \\
\hline Precipitation & $\begin{array}{l}\text { Vaisala VRG101 Weighing bucket Precipitation gauge (phasing out), } \\
\text { Hach Hydromet OTT Pluvio }{ }^{2} \text { weighing-bucket precipitation gauge } \\
\text { (5 years) }\end{array}$ \\
\hline Solar radiation & Apogee SP-110 incoming solar radiation pyranometer (3 years) \\
\hline Wetness & $\begin{array}{l}\text { Vaisala DRD-11A wetness sensor (retired), Campbell Scientific } 237 \\
\text { leaf wetness sensor ( } 5 \text { years) }\end{array}$ \\
\hline Field camera & Campbell Scientific CCFC field camera (select stations) (10 years) \\
\hline Soil temperature & Stevens Digital Hydraprobe-II sensor (5 years) \\
\hline Soil moisture & Stevens Digital Hydraprobe-II sensor (5 years) \\
\hline Barometric pressure & Vaisala PTB-110 barometer (2 years) \\
\hline \multicolumn{2}{|l|}{ Onsite data collection, power supply, and communication } \\
\hline Datalogger & Campbell Scientific CR3000 micrologger (5 years) \\
\hline Datalogger enclosure & Campbell Scientific ENC14/16 \\
\hline Solar panels & Solarcraft $140 \mathrm{~W}$ solar panel $\times 2(15$ years $)$ \\
\hline Solar controller & SunSaver solar controller (10 years) \\
\hline Solar enclosure & SolarCraft Econo-box EA5603 \\
\hline Battery & Duracell Ultra Deep Cycle $100 \mathrm{AH}$ battery $\times 2(7$ years $)$ \\
\hline Modem & Sierra Wireless RV50 cellular modem \\
\hline Antenna & Campbell Scientific 32262 Omni Antenna, Campbell Scientific \\
\hline Static dissipater & Lightning Prevention Systems ALS-100 \\
\hline Tower & Universal Tower, $30 \mathrm{ft}$ \\
\hline
\end{tabular}

\section{b. Relative humidity}

A Campbell Scientific EE-181 air temperature and relative humidity sensor is mounted at $1.5 \mathrm{~m}$ inside of a naturally aspirated R.M. Young 10-plate radiation shield, attached to the north side of the station tower (Fig. 5; Tables 1 and 2). While the temperature measurements from this sensor do not constitute the official temperature record, they provide a quality assurance check for use by the official Thermometrics PRT sensors described above. Relative humidity values range from $0 \%$ to $100 \%$ and are used to derive dewpoint temperature. Note that the Kentucky Mesonet started with a Vaisala HMP45C relative humidity sensor and then recently adopted the current sensor due to discontinuation of the previous sensor (Vaisala HMP45C) by the manufacturer.

\section{c. Solar radiation measurements}

The network uses the Apogee SP-110 pyranometer for incoming solar radiation measurement. It is secured above the aspirated radiation shield at $2 \mathrm{~m}$ (Tables 1 and 2). The sensor is mounted on the south side of the tower to ensure a clear sky view with maximum incoming solar radiation exposure. The network recently changed its solar radiation sensor from Apogee PYR-P to Apogee SP-110 due to discontinuation of the former by the manufacturer.

\section{d. Precipitation measurements}

At each station, an OTT Pluvio ${ }^{2}$ weighing-bucket precipitation gauge is located $6 \mathrm{~m}$ to the southeast of the main tower (Fig. 5). The opening of the gauge is at $1.5 \mathrm{~m}$ (Tables 1 and 2). The OTT Pluvio ${ }^{2}$ uses a strain gauge to measure the total weight of the bucket and the weight is converted to depth. The gauge CPU further calculates accumulated precipitation and precipitation intensity. Once that information is retrieved by the datalogger, the datalogger program calculates the change in $\mathrm{mm}$ as the official precipitation record. The Vaisala VRG101 gauge was chosen for all of the stations in the network during the initial deployment. The model was discontinued by the manufacturer and the OTT Pluvio ${ }^{2}$ gauge was selected as its replacement.

\section{e. Wind measurements}

An R.M. Young 05103 Wind Monitor is mounted at the top of the tower at $10 \mathrm{~m}$ (Tables 1 and 2). The datalogger samples the sensor for wind speed and wind direction every $3 \mathrm{~s}$. The samples are averaged over the 5-min 


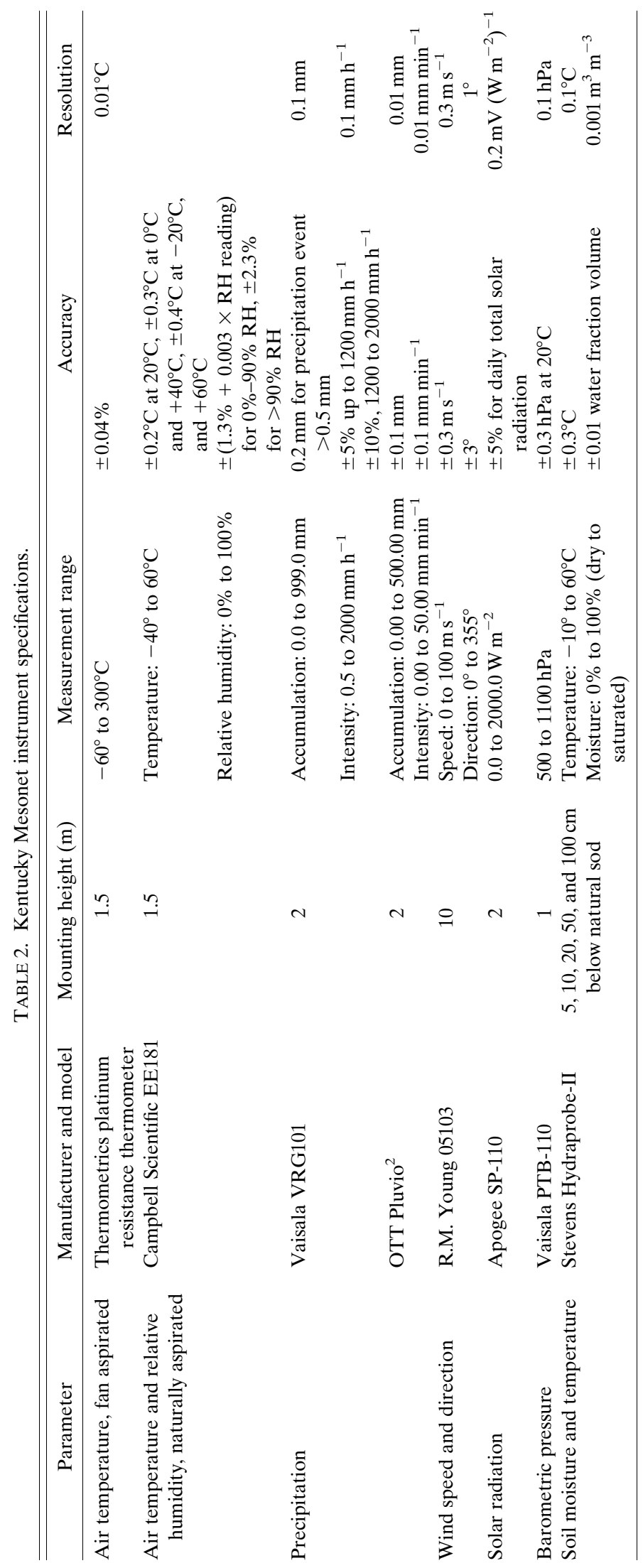




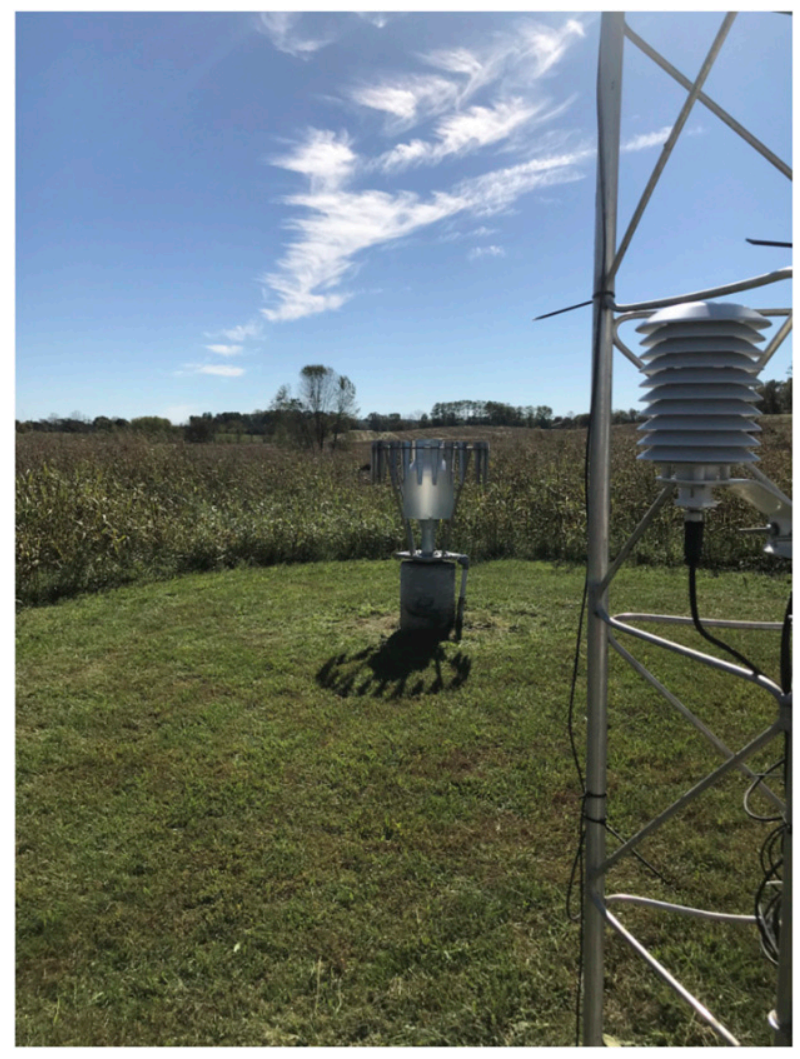

FIG. 5. Weighing-bucket precipitation gauge and relative humidity sensor.

period to get the official wind speed and direction record. In addition, the maximum and minimum 3-s values during the 5-min period are recorded as the official maximum wind gust and minimum wind speed. The wind direction at the time of the maximum wind gust is logged. The standard deviations of sampled wind speed and wind direction values are calculated within the datalogger program.

\section{f. Barometric pressure measurements}

The Kentucky Mesonet uses a Vaisala PTB-110 barometric pressure sensor located inside the datalogger enclosure on the main tower at approximately 1-m height (Tables 1 and 2). Mean sea level pressure is calculated during post processing based on the station elevation.

\section{g. Soil moisture and temperature measurements}

Currently, 35 Kentucky Mesonet stations observe soil moisture and temperature at 30-min intervals. At these stations, Stevens Hydraprobe-II digital soil monitoring sensors are located at $5,10,20,50$, and $100 \mathrm{~cm}$ below native sod (Figs. 6 and 7; Tables 1 and 2). The network plans to expand soil moisture and soil temperature monitoring to approximately three-quarters of the stations.

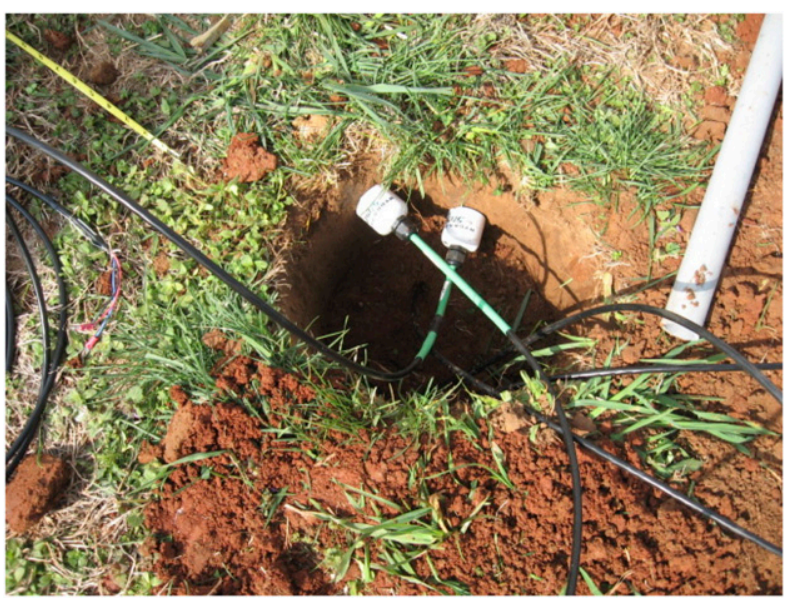

FIG. 6. Soil moisture and temperature sensors. They are placed at depths of $5,10,20,50$, and $100 \mathrm{~cm}$.

Some locations have disturbed soil or are on reclaimed strip mines or mountains, thus making it difficult to have representative soil monitoring.

\section{Communication and data acquisition}

Station data are stored on a Campbell Scientific CR3000 micrologger that is connected to a Sierra Wireless RV50 cellular modem. The RV50 connects to an AT\&T wireless custom Access Point Name powered by Cisco Jasper. Subsequently, collected data arrives at the Kentucky Mesonet data servers located at Western Kentucky University's Lost River Data Center. Servers for ingest, metadata, and public webpages provide (Fig. 3) the core of the Information Technology (IT)

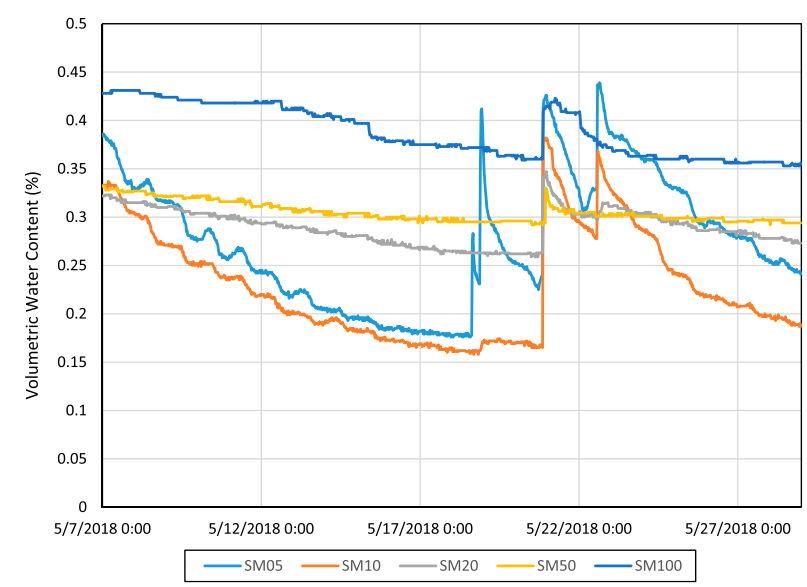

FIG. 7. Soil moisture distribution (30 min) at the Barren County Mesonet station for about a 3-week period. Soil moisture spikes were linked to two precipitation events and were particularly visible at depths of 5 and $10 \mathrm{~cm}$. 
infrastructure for data collection, processing, and product generation. The network had quite a few problems during the first few years of operation but ever since it transitioned to an AT\&T Control Center, there has been less than $1 \%$ downtime due to the cellular network.

\section{a. Data ingest server}

Data ingest is scheduled by using Campbell Scientific LoggerNet software. Data are subsequently stored in comma-separated values (CSV) files as raw data and are simultaneously inserted into the quality assurance queue and the MySQL database in near-real time. As data arrive, automated quality assurance tests are completed within seconds. Data are delivered to the public web server in less than a minute.

\section{b. Metadata database and product generation server}

After data ingest and quality assurance tests, data product generation is started and prepared for the public website. Some of the data product formats include JSON, XML, METAR, and CSV. Multiple databases operate using multimaster replication. One set of databases handles data storage. A second set stores metadata. Site survey records are stored in a third set of databases. With a duplicate of each database, a mirror database can become automatically operational without any interruption or loss of data in the event of a failure.

Product generation activities are closely linked to metadata maintenance activities. In the metadata server, data are maintained for each piece of instrumentation including manufacturer, model, serial numbers, vendor, Kentucky Mesonet internal identification number, calibration date and coefficients, date of field installation, repair information, trouble tickets, and site visits. The purpose of the station metadata is to provide detailed information related to observations. Metadata can be retrieved if a user makes a request. The Kentucky Mesonet operates an automated process that addresses any discrepancy in the database by notifying the information technology staff so that issues can be addressed.

Based on the observed data, the Kentucky Mesonet produces a series of interpolated maps using nearestneighbor interpolation and Python. These maps include air temperature, precipitation, solar radiation, relative humidity, wind speed, and wind direction. All products are exported to a public webserver for display and distribution.

\section{c. Public webserver}

The public webserver is the point of distribution for all internal and external products. Products available internally consist of a metadata database interface, daily network-wide quality assurance (QA) summary, and a detailed summary for each station in the network. Other internal products include a server uptime/availability report, dataset download interface, and custom mapping. Maps used for QA display station-specific metadata, such as battery voltage, precipitation gauge mass, and trouble ticket counts. Additionally, this web page serves as a test bed for new products before being publicly released.

External products viewable to the public are accessible on the main Kentucky Mesonet website (http:// www.kymesonet.org). Data services include maps, tables, and graphs. Maps show station location as well as the selected variable, generally with a color-filled contour background. The tables provide real-time data along with daily, monthly, and yearly summaries. Aside from concisely compiling daily summaries for a station, the monthly summaries further highlight the extrema for the period (the highest high temperature, lowest low temperature, etc.).

New products are added to the public website following thorough testing. Topic-specific tools are added when the need arises, such as pages for temperature inversion monitoring or the total solar eclipse of August 2017. The flexibility of the web page design allows for easy expansion of products and applications.

\section{Quality assurance}

High-quality data from stations are important for research and operational use. Hence, rigorous operational practices have been developed and implemented (e.g., Shafer et al. 2000; McPherson et al. 2007; Fiebrich et al. 2010). Further, a critical body of research has evolved to develop and assess methods to assure quality. The focus of this body of research has included identifying, analyzing and subsequently developing methods to overcome observation bias linked to site selection, exposure of instruments, maintenance of station(s), data collection, data processing, sensor limitations, and network density (e.g., Alter 1937; Robinson 1989; Meek and Hatfield 1994; DeGaetano 1997; Hubbard 2001; Duchon and Essenberg 2001; Hubbard et al. 2004, 2005, 2007; Hubbard and You 2005; Graybeal et al. 2004; You and Hubbard 2006, 2007; You et al. 2008; Durre et al. 2010). Hence, the purpose of Kentucky Mesonet QA system is to monitor the receipt of data and to assess data integrity. Suspicious data can arise from sensor errors and site exposure characteristics. Measurements can drift after sensors remain in the field for too long without calibration, resulting in biased observations. Exposure and siting issues may adversely affect the representativeness of data. Thus, the documentation of detailed station metadata are critical 
to support several levels of QA tests and necessary to ensure that data meet research-quality standards.

Redundant instrumentation, such as the deployment of three temperature sensors, aids in identification of bad data from an individual sensor. Intercomparison of data from different instruments, such as relative humidity and precipitation, at each site is also a key method to evaluate quality of moisture data. Each station has unique characteristics that influence the recorded data. For example, a station located on top of a ridge may have higher wind speeds than a station set in a valley. While these data are not bad, data may appear inconsistent with surrounding data, so accurate documentation of metadata is critical for QA.

Data QA is performed both by automated and manual procedures. Automated QA routines flag data values based on statistical rules, while manual QA is performed by Kentucky Mesonet staff, who inspect data using exploratory data-visualization tools and statistical methods to confirm that values are appropriately flagged. In some cases, manual QA evaluations may override determinations made by automated QA algorithms. A daily summary of all nonzero flags is automatically compiled and available for QA staff to further review and examine.

Station metadata recorded during site installation or maintenance are also vital in the determination of data quality. Metadata help to minimize the occurrence of two fundamental errors: good data marked as bad (type I error) or bad data marked as good (type II error). Investigation of meteorological conditions combined with metadata allows the QA staff to effectively assign the proper flag value to the data. The metadata database includes a table for meteorological event information. It connects the QA flag table automatically to a specified station, preventing bad data from being displayed to the public. Further details of the QA system are provided below.

\section{a. Sensor calibration}

Instruments selected for deployment are calibrated by the manufacturer or in the Kentucky Mesonet instrumentation laboratory and at the experimental testing bed located at the Western Kentucky University agriculture farm. Calibration methods were determined through recommendations taken from the manufacturer's instrument manual and review of other meteorological observing networks. Reference instruments are used for calibration to guarantee operational instruments are properly calibrated. With calibration, all sensors except precipitation and relative humidity, receive a calibration coefficient for applying to measured values to lie within the manufacturer's specifications. The instrumentation is then installed at the remote stations.

\section{b. Site maintenance}

Regular site visits play an important role in ensuring quality of data (e.g., Fiebrich et al. 2006). Kentucky Mesonet technicians perform three routine maintenance site visits every year during spring, summer, and fall seasons at each station. Duties include vegetation maintenance, instrumentation service, and photographic documentation.

Natural Kentucky vegetation can vary greatly throughout the state, from invasive Johnson grass and kudzu to brambles and trees. Because of the varying degrees of difficulty, field technicians must have the appropriate tools on hand to perform proper maintenance. The technicians are required to clear the station plot of significant vegetation during every site pass. This includes trimming grass, digging up trees or bushes to the roots, and removing vines from the fencing, tower, and instrumentation. In some cases, agreements with the site host are made, which involve grass seeding or herbicide application. This is typically the most strenuous task of a site visit.

Technicians thoroughly clean all instrumentation and sensor housings. The precipitation gauges must be manually emptied by taking the bucket off of the load cell and emptying into an appropriate container. A small amount of liquid must remain in the bucket to avoid errant precipitation data due to an unstable bucket. In the fall, gauges are loaded with antifreeze in order to inhibit the effects of frozen water on the precipitation data and housing. The remaining sensors and housings are gently wiped down with a moist microfiber cloth. Instrumentation is rotated on a schedule based on the manufacturer's recommendation (Table 1).

During each site pass visit, the technician is required to capture the station quality with photographic documentation. Site photos are taken with a digital camera set at its highest-quality setting. All photos are taken in landscape orientation, except for tower profiles and any notable findings. Photos are taken from the fence gate (or approximate location) upon arrival and departure in order to properly document conditions inside and outside of the station plot that could impact data before or after the visit. Additionally, the station's surroundings are photographed in each cardinal and ordinal direction for a panoramic view of potential siting changes. Any notable findings that could affect sensor readings, equipment performance, safety, or that document theft or vandalism are also thoroughly documented with photos. Examples of notable findings would be wasp nests in the temperature radiation shield, mice in the datalogger enclosure, and visible lightning damage. Stations with soil probes require additional photos of the sod soil plot for record of vegetation cover. Profile and landscape 
photos are taken of the tower as the technician leaves the station.

Problems that arise between scheduled visits are investigated and a trouble ticket describing the problem, suggested actions to take, and priority value is assigned if the problem requires human intervention. Hence, technicians make additional site visits as needed.

\section{c. Automated and manual quality assurance tests}

It has been shown by Fiebrich and Crawford (2009) that automation of the quality assurance process helped to improve overall data quality of the Oklahoma Mesonet. In the case of the Kentucky Mesonet, raw data are inserted into a database upon retrieval from a station. The raw data are queried-never changed-from the database to apply QA methods. Automated QA is a series of computer scripts written to perform preliminary checks on the data. QA runs at different intervals for various aggregations of data, from real time to daily to monthly. Real-time QA includes simple filters to discern data collected when a technician was present at a station (i.e., datalogger enclosure door is open), data that failed a range test, and/or data values that have been determined as bad by the QA specialist (e.g., a bad sensor). This prevents bad data from going public and being used for real-time decisions.

If a data value fails to pass any individual step of this process, it does not proceed to the next step until it is manually checked by the QA staff. At this point, the data value is assigned a quality value based on the confidence of the data being valid or invalid.

The first automated test is an instrument range check. The simplest of all the tests, the range check makes sure each data value is within the manufacturer-specified range. As more data are collected over time, a set of upper and lower bounds can be determined to modify the range test for Kentucky climate extremes. If a value fails this test, it is marked as "failure" and does not proceed further in the automated QA process.

Another important feature is redundant instrumentation at the stations. One example is temperature measurement: three fast-response temperature sensors are located inside of an aspirated shield and a slower-response temperature and relative humidity sensor is located inside an unaspirated shield. While only the three aspirated sensors are used for the official air temperature calculation, the additional unaspirated sensor assists in the QA process by providing an upper limit of reasonable air temperature at the given time. This redundancy largely negates the need for spatial temperature comparisons using proximate stations and increases confidence in temperature measurements. After all steps have been completed, the final QA flag for the data value is stored in an associated table.
After quality flags have been applied to the data, the QA staff review the data manually via visual aids (meteograms, scatterplots, line graphs, etc.) and reference supplemental information for the final approval of the data.

The following sections provide details on automated and manual QA tests that are specific to each variable.

\section{1) Temperature}

The application of QA flags for temperature measurement is illustrated in the following scenarios. If the difference between TA01 and TA02 is greater than $0.3^{\circ} \mathrm{C}$ but the differences between TA 01 and TA 03 and also TA02 and TA03 are less than $0.3^{\circ} \mathrm{C}$, then the data values TA01 and TA02 are identified as "suspect." If the temperature differences are more than $0.3^{\circ} \mathrm{C}$ for two pairs, then the common sensor is flagged as "warning." Sensors flagged as warning are not included in the calculation of TAIR. Sensors are most likely to stray from each other when there is 1) calm wind, 2) a precipitation event, 3) rapid change in solar radiation, or 4) nonfunctioning aspirated shield fan.

In addition to the temperature sensor intercomparison, the TAIR value is checked against the naturally aspirated EE-181 (Vaisala HMP45C prior to adoption of EE-181) temperature sensor value. The EE-181 values can stray from the TAIR value by about $1^{\circ} \mathrm{C}$ due to the difference in aspiration. Note that natural-aspiration results in higher temperature observations by the EE-181, which are particularly amplified during the warm season (Fig. 8a). The magnitude of this warm bias is reduced during high wind periods (Fig. 8b). In addition, the EE-181 is not used to set a flag for TAIR or the individual PRT sensors due to the fundamental differences in instrument and shield characteristics, but the variable is useful for comparison.

When a problem is noticed, the incorrect sensor is flagged as suspect and should be closely monitored until it is replaced. The source of the problem is investigated before a trouble ticket is issued to ensure quick and adequate solution.

\section{2) Relative HUMidity}

While it is meteorologically possible, the EE181 sensor (and the previous sensor, HMP45C) is not capable of accurately measuring relative humidity above $100 \%$. All reported data points between $100 \%$ and $103 \%$ are changed to $100 \%$. Any observation above $103 \%$ is flagged as failure. Sensors that consistently report out-of-range relative humidity observations have likely fallen out of calibration or there is a problem with the radiation shield or sensor filter. A trouble ticket is assigned to the variable and the technicians are asked to inspect the radiation shield and to switch out the relative humidity sensor with a known 
a)

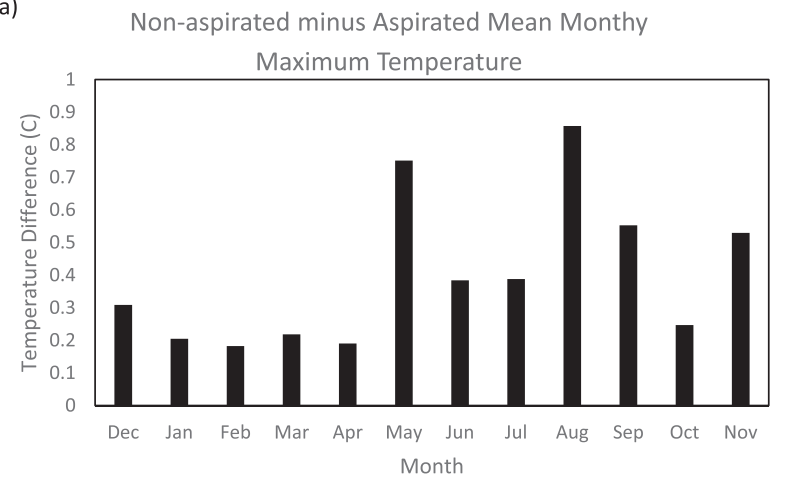

Non-aspirated minus Aspirated Mean Monthly

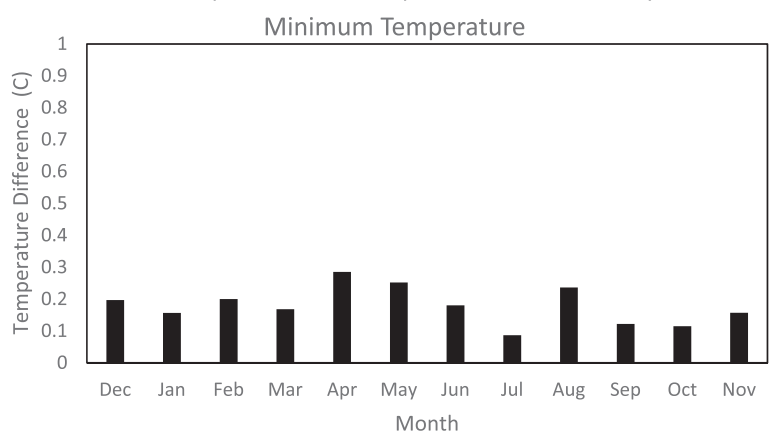

b)

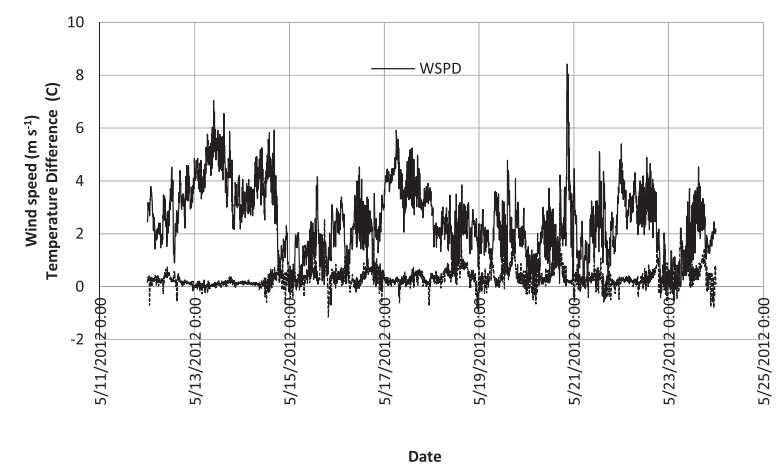

FIG. 8. (a) Monthly temperature difference between nonaspirated and aspirated sensors during December 2011-November 2012 for the Christian County Station. Nonaspirated sensor consistently recorded higher temperature compared to aspirated sensor. (b) The 5-min wind speed (WSPD) and temperature difference between nonaspirated and aspirated sensors for a 2 -week period. It is clear that as wind speed increases, temperature difference between nonaspirated and aspirated sensors decreases.

good sensor and bring back the bad sensor to the laboratory for assessment.

\section{3) SOLAR RADiATION}

The U.S. Naval Observatory is referenced for times of sunrise and sunset. In addition, the earliest and the latest sunrise and sunset times, respectively, are considered to ensure accuracy of solar radiation observations.
All nighttime values that are nonzero may be corrected to 0 in the QA dataset after manual QA approval. While it may seem better to automatically correct the nonzero values within the datalogger program, correction of these values may mask a sensor problem that would otherwise go unnoticed throughout the day. An algorithm will be adopted or developed to project the maximum possible solar radiation given a specified latitude and longitude and the time of day and year. However, currently, we use a clear-sky solar radiation model for manual QA (http:// clearskycalculator.com/pyranometer.htm). On an otherwise clear day (maximum solar radiation), shadows cast from the guy wires may cause momentary dips but should return to normal within a few observations.

\section{4) Precipitation}

As noted above, all Kentucky Mesonet stations were originally equipped with a Vaisala VRG101 weighing bucket precipitation gauge. Vaisala discontinued this product and as a result, the Kentucky Mesonet started to replace VRG101 gauges with Hach Hydromet OTT Pluvio ${ }^{2}$ weighing-bucket gauges in 2016. Thus, an overview is provided for the quality assurance tests for both gauges.

Proprietary internal algorithms control the VRG101. Accumulated dew is not recorded as precipitation, and evaporated liquid is not recorded as negative precipitation. Another algorithm within the VRG101's CPU calculates precipitation intensity (PRTE). Intensities below $0.5 \mathrm{~mm} \mathrm{~h}^{-1}$ are reported as $0 \mathrm{~mm} \mathrm{~h}^{-1}$. During winter months, ice can accumulate in between the funnel and bucket, causing false reports of highintensity precipitation. The calculations for both PRTE and the 5-min precipitation total create a problem with the correct time-stamp of data, as there can be up to a 15-min delay in the report of precipitation (Vaisala All-Weather Precipitation Gauge VRG101 User's Guide).

The first QA check for precipitation is a feasibility check, using the wetness sensor and relative humidity sensor readings. The wetness sensor is highly sensitive to moisture and is a good indicator of rainfall. Relative humidity is expected to generally increase during a precipitation event. Next, satellite, radar, and reported solar radiation are examined to evaluate sky conditions.

As the OTT Pluvio ${ }^{2}$ gauge has been incorporated into the network, QA procedures for the data have generally remained the same. The key difference lies in the response time of the gauge. The Pluvio ${ }^{2}$ is capable of updating on a 1-min resolution scale, greatly increasing the efficiency in providing data in a timely manner. 


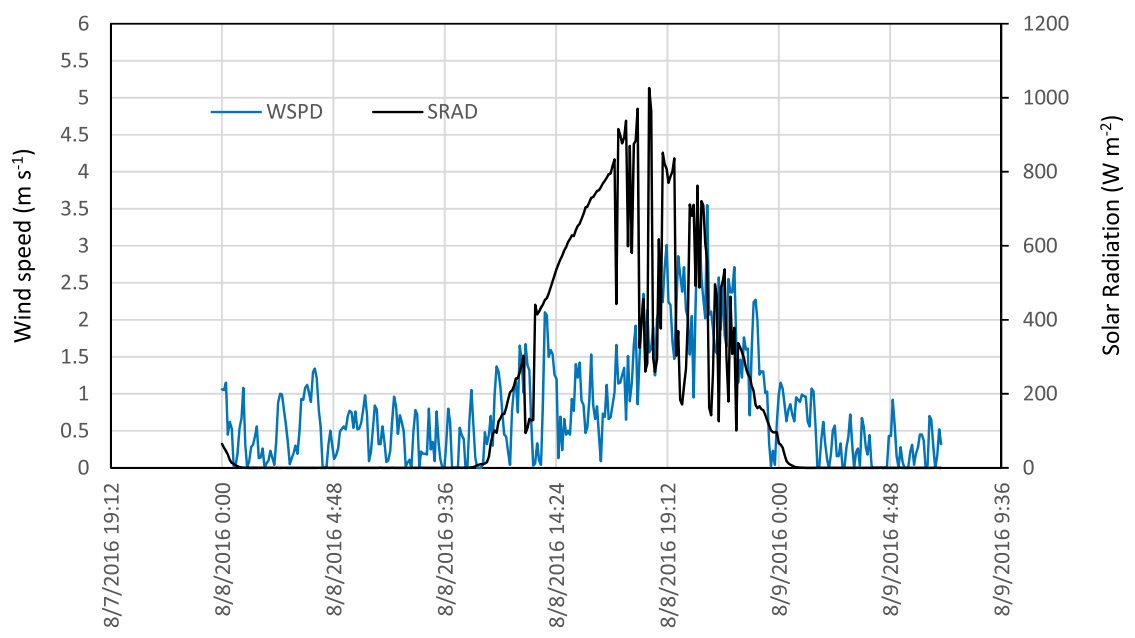

FIG. 9. Diurnal changes in wind speed (WSPD) and solar radiation (SRAD).

\section{5) WIND}

Wind speeds have a strong diurnal variation, unless modified by significant synoptic or mesoscale conditions. Wind speeds commonly approach calm $\left(<0.5 \mathrm{~m} \mathrm{~s}^{-1}\right)$ during overnight hours and reach a maximum during daylight hours due to diurnal changes in atmospheric stability forced by solar radiation (Fig. 9). When wind speed is below the R.M. Young Wind Monitor's starting threshold (propeller: $1 \mathrm{~m} \mathrm{~s}^{-1}$; vane: $1.1 \mathrm{~m} \mathrm{~s}^{-1}$ ) all wind measurements (speed and direction) are changed to zero. This includes calculated minima, maxima, and standard deviations. Wind direction is measured between $0^{\circ}$ and $355^{\circ}$ with $5^{\circ}$ increments. Reported wind direction values while wind is calm are not included in the calculation of any period averages (i.e., daily average wind direction). During the QA process, weather conditions are considered when assessing wind data. During severe winter weather, wind monitors can become coated by frozen precipitation, thus providing measurements of zero for all wind variables even though the true wind speed could be greater.

\section{6) Datalogger enclosure}

The state of whether the datalogger enclosure door is open or closed is monitored and recorded. If the datalogger door is opened, the data are automatically flagged as erroneous. Subsequently, data are manually reviewed by QA staff in an effort to eliminate data flags on good data points. Weather conditions at the time of site maintenance may not allow the technician to leave the enclosure door open. In this case, the QA staff will manually flag the data from the initial door opening upon arrival until the technician calls to notify of departure.

\section{7) BATTERY VOLTAGE}

Supply voltages for the datalogger (BATV) and weighing bucket rain gauge (RGBV) are recorded at each station. Solar power is currently the most widely used power system in the network (eight are AC powered). This is a concern during winter months when solar radiation is reduced and aspirated shield fan operation quickly drains battery power.

For solar powered stations (63 of 71 stations), the network observes battery behavior to determine health of the battery. The aspirated shield fans are automatically turned off when battery voltage drops below $11.7 \mathrm{~V}$ and resume operation when station voltage reaches $12.2 \mathrm{~V}$. If batteries do not charge during time of sunlight, the QA specialist promptly notifies field technicians as this could be a result of damaged electronics, severely dirty solar panels, or a dead battery.

\section{8) QUALITY ASSURANCE REPORTS}

Quality assurance reports are automatically generated daily and distributed to the QA staff and field technicians. To ensure data users are aware of the possibility of compromised data, QA reports composed by the QA specialist can be released upon request. The monthly QA report contains a general overview of maintenance performed, a brief summary of significant weather, and trouble tickets open or closed during the period.

\section{Applications}

As data are becoming "mature," the Kentucky Mesonet has started to develop a variety of decision tools. These tools include data and data derived products and are available via the World Wide Web and mobile apps for 
a)

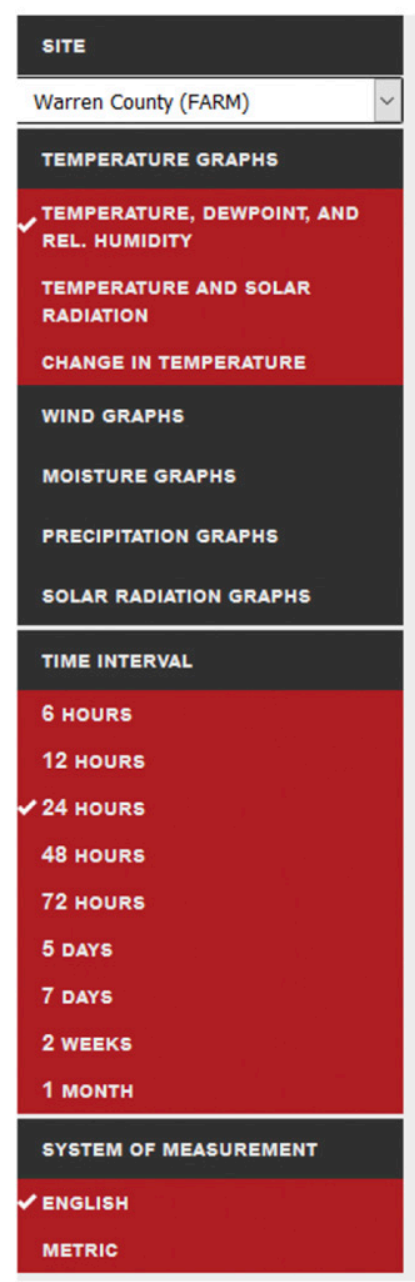
FARM Temperature, Dewpoint, and Relative Humidity (24 Hour)

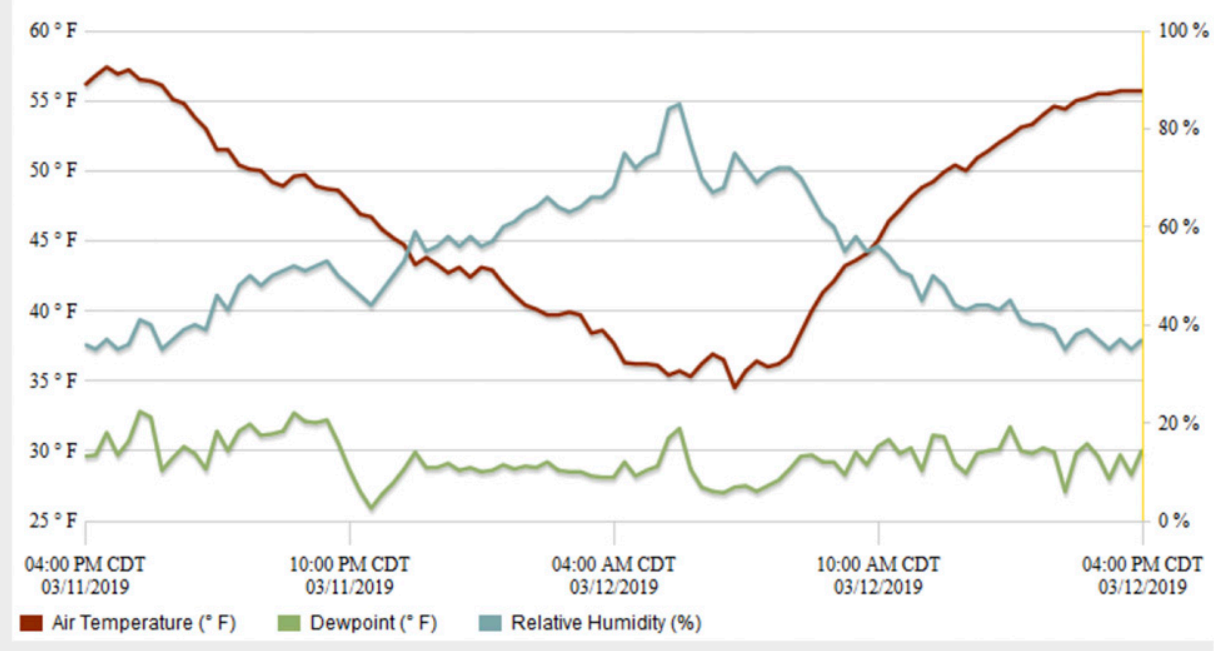

\begin{tabular}{|c|c}
\hline Station & Warren County, $\mathrm{KY}$ \\
\hline Time & $03 / 12 / 2019,04: 00 \mathrm{PM}$ CDT \\
\hline Air Temperature & $55.7^{\circ} \mathrm{F}$ \\
\hline Relative Humidity & $37^{\circ} \mathrm{F}$ \\
\hline Precipitation & $0.00 \mathrm{in.}$ \\
\hline Wind Speed & $8 \mathrm{mph}$ \\
\hline Wind Direction & $83^{\circ}$ (E) \\
\hline Wind Speed Max Gust & $11 \mathrm{mph}$ \\
\hline Solar Radiation & $287 \mathrm{~W}^{\circ} \mathrm{m}^{2}$ \\
\hline Dewpoint & $30.1^{\circ} \mathrm{F}$ \\
\hline
\end{tabular}

FIG. 10. Examples of applications of Kentucky Mesonet data: (a) data product, (b) growing degree-day tool, (c) water management tool, and (d) total solar eclipse special project.

iPhone and androids. Any users or visitors of the Kentucky Mesonet website find statewide maps of all observed variables, except soil moisture and soil temperature. The maps update every $5 \mathrm{~min}$ as data arrive from all sites. The maps nicely show state-wide spatial variations in near-surface atmospheric conditions. A user can also select any Kentucky Mesonet station and any of the observed variables and plot these data for windows ranging from $6 \mathrm{~h}$ to 1 month (Fig. 10a). The computer cursor can be moved over any line showing a variable to display observed values. A complementary tabular display of data is synchronized with the graphical display.

Other popular data products include a daily top-10 accumulated precipitation, maximum and minimum temperature, and maximum wind since midnight. The
Kentucky Mesonet website also displays daily data, month by month, for all observed variables for all stations for the period of record. Similarly, monthly data can be viewed for all stations and for the period of record.

The Kentucky Mesonet has been working with various stakeholders to develop decision tools for different economic sectors. Through these collaborations, for example, a growing degree-day (GDD) tool has been developed for corn, soybean, and wheat to assist farming communities (Fig. 10b). To assist water managers, water management tools were developed for subregional level via active collaboration with this group (Fig. 10c). Currently, the Kentucky Mesonet is in the process of expanding these tools for the entire state. 
b)

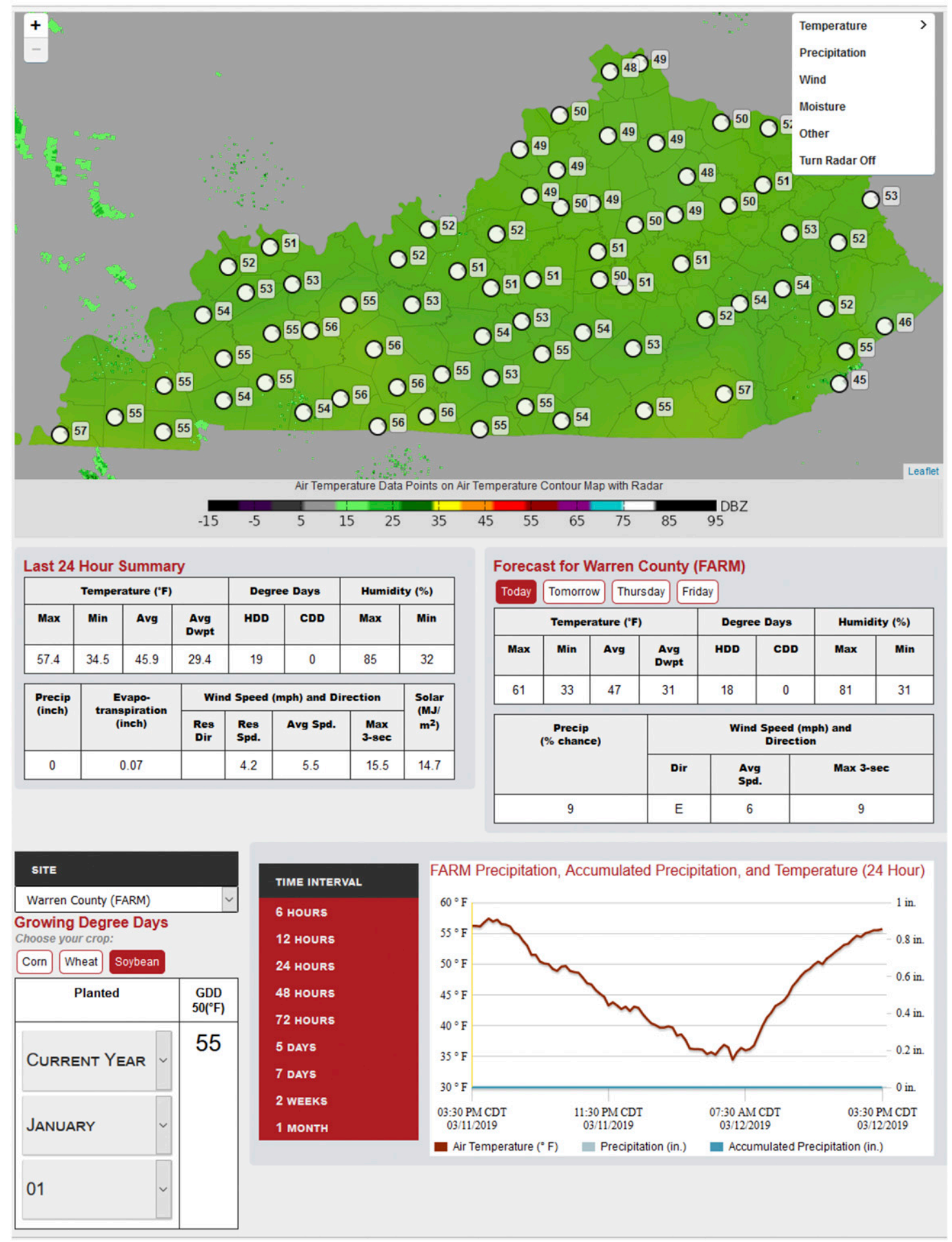

FIG. 10. (Continued) 
c)

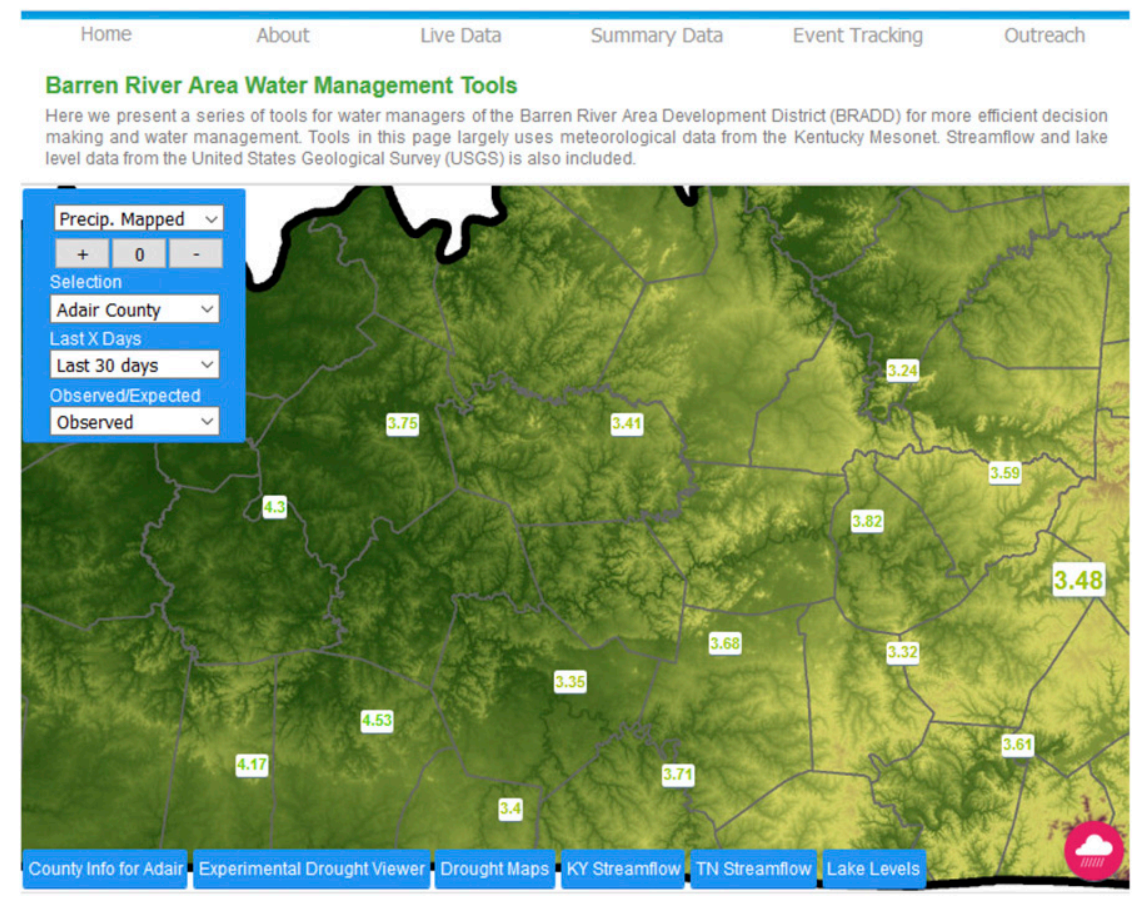

FIG. 10. (Continued)

As expected, the Kentucky Mesonet has developed a strong partnership with the National Weather Service and provides data to the five offices that forecast weather for the state. In addition, the network provides data to the Kentucky Division of Water to support drought monitoring and assessment in Kentucky. The network has also developed collaboration with the National Integrated Drought Information System and is in the process of developing a program to support drought early warning and preparedness. This project is expanding current soil moisture and soil temperature monitoring capabilities. Data are also provided to Kentucky's Farm Service Agency in support of the Livestock Indemnity Program.

Moreover, the network has undertaken special projects. For example, during the historic total solar eclipse of 2017 (first in 99 years over the United States), the Kentucky Mesonet made extensive efforts to collect data for scientific research. This is a unique set of meteorological data to study the surface atmospheric response to a total solar eclipse at the mesoscale (Fig. 10d). Recently, the Kentucky Mesonet has embarked on another special project focusing on monitoring and understanding near-surface temperature inversions. The Kentucky Mesonet has prioritized student-led research, including assessment of mesoscale near surface atmospheric heat content (Younger et al. 2019;
Na-Yemeh 2017), with a wide range of opportunities available for future projects.

\section{Conclusions}

The Kentucky Mesonet has been developed as a research-grade network for monitoring weather and climate. The design philosophy, including instrument selection and operational approach, largely followed the U.S. Climate Reference Network (USCRN) and the Oklahoma Mesonet. Since its existence, the Kentucky Mesonet has delivered data directly to the local National Weather Service Offices that serve Kentucky to aid in daily forecasting and during severe weather conditions. In addition, the network has developed strong relationships with local and state government entities and other stakeholders (e.g., local elected officials, emergency managers, agricultural extension agents, water managers) to build support for the network and direct the development of products and services to assist decision-makers. Reflecting these successes, the Kentucky Mesonet has developed an increasingly diversified revenue stream that includes core operating support from the Commonwealth of Kentucky supplemented by local sponsorship revenue and funding from the National Mesonet Program (NMP). Thus, the network continues to grow, increasing its 
d)

Total Solar Eclipse 2017 in Kentucky

On August 21, 2017, a total solar eclipse passed across the entire continental United States, from the Pacific Ocean to the Atlantic Ocean. While total solar eclipses occur about every 18 months, most occur over the oceans. This total solar eclipse was unique because the path of totality was visible to millions of people as it transited North America.

\section{What We Did:}

On the day of the eclipse, the Kentucky Mesonet recorded data from all 68 stations every 3 seconds for incoming solar radiation, air temperature, wind direction, and wind speed. Data was brought back every minute and air temperature and solar radiation maps were updated every minute. The Hopkinsville, KY station data was brought back every 3 seconds for a live graph (final product pictured below).

\section{Kentucky Mesonet Christian County Temperature and Solar Radiation}

$95^{\circ} \mathrm{F}$

$90^{\circ} \mathrm{F}$

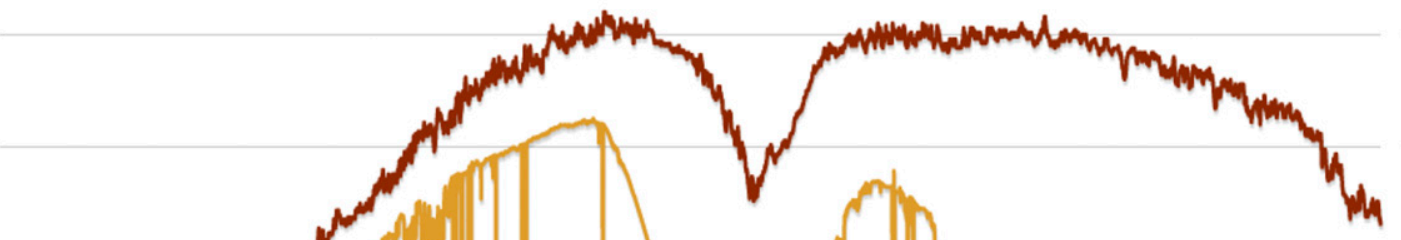

1000

$\mathrm{W} / \mathrm{m}^{2}$

$85^{\circ} \mathrm{F}$

$80^{\circ} \mathrm{F}$

$75^{\circ} \mathrm{F}$

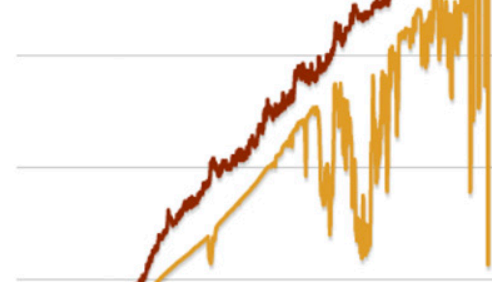

$70^{\circ} \mathrm{F}$

$65^{\circ} \mathrm{F}$

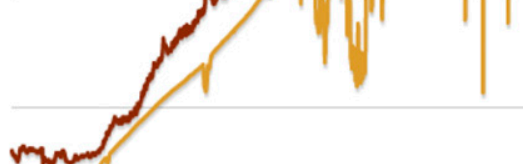

05:57:21 AM CDT

$\begin{array}{cc}05: 57: 21 \text { AM CDT } & 07: 57: 33 \text { AM CDT } \\ 08 / 21 / 2017 & 08 / 21 / 2017\end{array}$

08/21/2017

09:57:45 AM CDT

Air Temperature ( $\left.{ }^{\circ} \mathrm{F}\right) \quad$ Solar Radiation $\left(\mathrm{W} / \mathrm{m}^{2}\right)$

About Solar Radiation:

Solar Radiation is one of the many variables the Kentucky Mesonet measures from our network of weather stations across the state. Simply put, solar radiation data provides information on how much of the sun's energy reaches a location on Earth during a particular time, represented as a Watt per meter squared $\left(\mathrm{W} / \mathrm{m}^{2}\right)$. The intensity of solar radiation is a function of the angle of sunlight reaching a point on the Earth. Cloud cover, air pollution, and water vapor are just a few factors that can influence the amount of solar radiation measured at the Earth's surface.

\section{FIG. 10. (Continued)}

footprint and expanding its instrumentation suite. While uncertainties regarding future funding are inherent, the Kentucky Mesonet is positioned to leverage ongoing investment in the network to support research, service, and outreach initiatives for the benefit of citizens in Kentucky and beyond.

Acknowledgments. The authors gratefully acknowledge valuable contributions made by Mike Grogan, Stephen Struebig, and Dana Grabowski during early implementation of the Kentucky Mesonet. We thank three reviewers for their valuable feedback that helped to improve this paper. Thanks also to Gerardo Diaz and William Rodgers for their assistance in preparation of Fig. 3.

\section{REFERENCES}

Alter, J. C., 1937: Shielded storage precipitation gages. Mon. Wea. Rev., 65, 262-265, https://doi.org/10.1175/1520-0493(1937) $65<262:$ SSPG $>2.0 . \mathrm{CO} ; 2$.

Brock, F. V., K. C. Crawford, R. L. Elliott, G. W. Cuperus, S. J. Stadler, H. L. Johnson, and M. D. Eilts, 1995: The Oklahoma Mesonet: A technical overview. J. Atmos. Oceanic Technol., 12, 5-19, https://doi.org/10.1175/1520-0426(1995)012<0005: TOMATO $>2.0 . \mathrm{CO} ; 2$. 
Brown, P. W., and K. G. Hubbard, 2001: Lessons from the North American experience with automated weather stations. Automated weather stations for application in agriculture and water resources management, K. G. Hubbard and M. V. K. Sivakumar, Eds., WMO/TD 1074, 21-28, http://www.wamis.org/agm/pubs/ agm3/WMO-TD1074.pdf.

DeGaetano, A. T., 1997: A quality-control routine for hourly wind observations. J. Atmos. Oceanic Technol., 14, 308-317, https://doi.org/10.1175/1520-0426(1997)014<0308:AQCRFH> 2.0.CO;2.

Diamond, H. J., and Coauthors, 2013: U.S. Climate Reference Network after one decade of operations: Status and assessment. Bull. Amer. Meteor. Soc., 94, 485-498, https://doi.org/ 10.1175/BAMS-D-12-00170.1.

Duchon, C. E., and G. R. Essenberg, 2001: Comparative rainfall observations from pit and above ground rain gauges with and without shields. Water Resour. Res., 37, 3253-3263, https:// doi.org/10.1029/2001WR000541.

Durre, I., M. J. Menne, B. E. Gleason, T. G. Houston, and R. S. Vose, 2010: Comprehensive automated quality assurance of daily surface observations. J. Appl. Meteor. Climatol., 49, 1615-1633, https://doi.org/10.1175/2010JAMC2375.1.

Fiebrich, C. A., and K. C. Crawford, 2009: Automation: A step toward improving the quality of daily temperature data produced by climate observing networks. J. Atmos. Oceanic Technol., 26, 1246-1260, https://doi.org/10.1175/2009JTECHA1241.1.

—, D. A. Grimsley, R. A. McPherson, K. A. Kesler, and G. R. Essenberg, 2006: The value of routine site visits in managing and maintaining quality data from the Oklahoma Mesonet. J. Atmos. Oceanic Technol., 23, 406-416, https://doi.org/10.1175/ JTECH1852.1.

—, C. R. Morgan, A. G. McCombs, P. K. Hall Jr., and R. A. McPherson, 2010: Quality assurance procedures for mesoscale meteorological data. J. Atmos. Oceanic Technol., 27, 15651582, https://doi.org/10.1175/2010JTECHA1433.1.

Graybeal, D. Y., A. T. DeGaetano, and K. L. Eggleston, 2004: Improved quality assurance for historical hourly temperature and humidity: Development and application to environmental analysis. J. Appl. Meteor., 43, 1722-1735, https://doi.org/10.1175/ JAM2162.1.

Horel, J., and Coauthors, 2002: Mesowest: Cooperative mesonets in the western United States. Bull. Amer. Meteor. Soc., 83, 211-226, https://doi.org/10.1175/1520-0477(2002)083<0211: MCMITW $>2.3 . \mathrm{CO} ; 2$.

Hubbard, K. G., 2001: Multiple station quality control procedures. Automated weather stations for application in agriculture and water resources management, K. G. Hubbard and M. V. K. Sivakumar, Eds., WMO/TD 1074, 133-136, http:// www.wamis.org/agm/pubs/agm3/WMO-TD1074.pdf.

, and J. You, 2005: Sensitivity analysis of quality assurance using the spatial regression approach-A case study of the maximum/minimum air temperature. J. Atmos. Oceanic Technol., 22, 1520-1530, https://doi.org/10.1175/ JTECH1790.1.

, N. J. Rosenberg, and D. C. Nielsen, 1983: Automated weather data network for agriculture. J. Water Resour. Plann. Manage., 109, 213-222, https://doi.org/10.1061/(ASCE)07339496(1983)109:3(213).

_- X. X. Lin, C. B. Baker, and B. Sun, 2004: Air temperature comparison between the MMTS and the USCRN temperature systems. J. Atmos. Oceanic Technol., 21, 1590-1597, https://doi.org/10.1175/1520-0426(2004)021<1590:ATCBTM> 2.0.CO;2.
— S. Goddard, W. D. Sorensen, N. Wells, and T. T. Osugi, 2005: Performance of quality assurance procedures for an applied climate information system. J. Atmos. Oceanic Technol., 22, 105-112, https://doi.org/10.1175/JTECH-1657.1.

— N. N. B. Guttman, J. You, and Z. Chen, 2007: An improved QC process for temperature in the daily cooperative weather observations. J. Atmos. Oceanic Technol., 24, 206-213, https:// doi.org/10.1175/JTECH1963.1.

Kimball, S. K., M. S. Mulekar, S. Cummings, and J. Stamates, 2010: The University of South Alabama Mesonet and Coastal Observing System: A technical and statistical overview. J. Atmos. Oceanic Technol., 27, 1417-1439, https://doi.org/10.1175/ 2010JTECHA1376.1.

Leeper, R. D., J. Rennie, and M. A. Palecki, 2015: Observational perspectives from U.S. Climate Reference Network (USCRN) and Cooperative Observer Program (COOP) Network: Temperature and precipitation comparison. J. Atmos. Oceanic Technol., 32, 703-721, https://doi.org/10.1175/JTECHD-14-00172.1.

Mahmood, R., and Coauthors, 2017: Mesonets: Mesoscale weather and climate observations for the United States. Bull. Amer. Meteor. Soc., 98, 1349-1361, https://doi.org/10.1175/ BAMS-D-15-00258.1.

McPherson, R. A., and Coauthors, 2007: Statewide monitoring of the mesoscale environment: A technical update on the Oklahoma Mesonet. J. Atmos. Oceanic Technol., 24, 301-321, https://doi.org/ 10.1175/JTECH1976.1.

Meek, D. W., and J. L. Hatfield, 1994: Data quality checking for single station meteorological databases. Agric. For. Meteor., 69, 85-109, https://doi.org/10.1016/0168-1923(94)90083-3.

Menne, M. C., N. Williams Jr., and R. S. Vose, 2009: The U.S. Historical Climatology Network monthly temperature data, version 2. Bull. Amer. Meteor. Soc., 90, 993-1008, https:// doi.org/10.1175/2008BAMS2613.1.

Meyer, S. J., and K. G. Hubbard, 1992: Nonfederal automated weather stations and networks in The United States and Canada: A preliminary survey. Bull. Amer. Meteor. Soc., 73, 449-457, https://doi.org/10.1175/1520-0477(1992)073<0449: NAWSAN $>2.0 . \mathrm{CO} ; 2$.

Na-Yemeh, D., 2017: Synoptic atmospheric conditions, land cover, and equivalent temperature variations in Kentucky. M.S. thesis, Dept. of Geography and Geology, Western Kentucky University, 127 pp., https://digitalcommons.wku.edu/theses/1930.

Robinson, D. A., 1989: Evaluation of the collection, archiving, and publication of daily snow data in the United States. Phys. Geogr., 10, 120-130, https://doi.org/10.1080/ 02723646.1989.10642372.

Schroeder, J. L., W. S. Burgett, K. B. Haynie, I. Sonmez, G. D. Skwira, A. L. Doggett, and J. W. Lipe, 2005: The West Texas Mesonet: A technical overview. J. Atmos. Oceanic Technol., 22, 211-222, https://doi.org/10.1175/JTECH-1690.1.

Shafer, M. A., C. A. Fiebrich, D. S. Arndt, S. E. Fredrickson, and T. W. Huges, 2000: Quality assurance procedures in the Oklahoma Mesonet. J. Atmos. Oceanic Technol., 17, 474-494, https://doi.org/10.1175/1520-0426(2000)017<0474:QAPITO> 2.0.CO;2.

Shulski, M., S. Cooper, G. Roebke, and A. Dutcher, 2018: The Nebraska Mesonet: Technical overview of an automated state weather network. J. Atmos. Oceanic Technol., 23, 406-416, https://doi.org/10.1175/JTECH-D-17-0181.1.

Tucker, D. F., 1997: Surface mesonets of the western United States. Bull. Amer. Meteor. Soc., 78, 1485-1495, https:// doi.org/10.1175/1520-0477(1997)078<1485:SMOTWU>2.0.CO;2. 
World Meteorological Organization, 2014: Guide to meteorological instruments and methods of observation. 8th ed. World Meteorological Organization Rep. WMO-8, 1139 pp.

You, J., and K. G. Hubbard, 2006: Quality control of weather data during extreme events. J. Atmos. Oceanic Technol., 23, 184197, https://doi.org/10.1175/JTECH1851.1.

- and — 2007: Relationship of flagging frequency to confidence intervals in the statistical regression approach for automated quality control of $T_{\max }$ and $T_{\min }$. Int. J. Climatol., 27, 1257-1263, https://doi.org/10.1002/joc.1484.
, and S. Goddard, 2008: Comparison of methods for spatially estimating station temperatures in a quality control system. Int. J. Climatol., 28, 777-787, https://doi.org/10.1002/joc.1571.

Younger, K., R. Mahmood, G. Goodrich, R. A. Pielke Sr., and J. Durkee, 2019: Mesoscale surface equivalent temperature $\left(T_{\mathrm{E}}\right)$ for East Central USA. Theor. Appl. Climatol., 136, 65-75, https://doi.org/10.1007/s00704-018-2468-7.

Ziolkowska, J. R., and Coauthors, 2017: Benefits and beneficiaries of the Oklahoma Mesonet: A multisectoral ripple effect analysis. Wea. Climate Soc., 9, 499-519, https://doi.org/10.1175/WCAS-D-16-0139.1. 